\title{
Development and Implementation of a Self-Study Roadmap for Part-Time Students
}

\author{
André von Zobeltitz (Corresponding Author) \\ Dept. of Business Economics, University of Applied Sciences Weserbergland \\ Am Stockhof 2, D-31785 Hamelin, Germany
}

Tel: 49-5151-9559-43Ｅ-mail: vonzobeltitz@hsw-hameln.de

Knut Linke

Institute for Knowledge Management, University of Applied Sciences Weserbergland Am Stockhof 2, D-31785 Hamelin, Germany

Tel: 49-5151-9559-56 E-mail: linke@hsw-hameln.de

\begin{abstract}
Eva Blochberger
Institute for Knowledge Management, University of Applied Sciences Weserbergland Am Stockhof 2, D-31785 Hamelin, Germany
\end{abstract}

Tel: 49-5151-9559-60Ｅ-mail: blochberger@hsw-hameln.de

Received: August 14, 2018

doi:10.5296/jet.v5i2.13411
Accepted: August 22, 2018

Published: August 20, 2018

URL: http://dx.doi.org/10.5296/jet.v5i2.13411

\begin{abstract}
The "Open IT" research project is being carried out in the scope of the federal state "Aufstieg durch Bildung: offene Hochschulen" initiative ("Advancement through education: open universities") in which credit transfer programmes are being designed for IT practitioners in Germany. In this process, research is being carried out into the development, implementation and use of methods to support self-study, which will be prepared for transfer to teaching. The use of a self-study roadmap for students and lecturers has been developed in the course of this research. This self-study roadmap supports students' time management and the balance of study, work and family.
\end{abstract}


Following the numerous evaluation steps involved in the creation of the self-study roadmap, the roadmap has been formally implemented and developed within the research project. The benefits, use and challenges of this learning tool are analysed and reflected upon in this paper in the context of education management. A strategic point of view has been chosen so that the tool can be examined on a meta level. The relevant perspective of the university, lecturers and students has been adopted so that an all-encompassing view can be guaranteed at strategic level.

Keywords: learning administration, self-study roadmap, part time studies, business informatics, special credit programs

\section{Introduction}

Study programmes for working professionals are growing in importance within society, due in part to the increasingly necessary life-long learning of employees. Education providers in the tertiary field, who in the past mainly offered full-time programmes for their students, are increasingly obliged to adequately serve the target group of students holding full-time jobs. This also includes satisfying the needs of this target group by offering appropriate services.

Time management in relation to studying is a particular challenge for students on study programmes for working professionals as this target group a) is working and has to balance work and study and b) usually has a family or, due to the generally higher age of participants, a personal life that takes up much of their time. It is consequently of greater importance to make methods and support programmes available to this target group that improve the balance of study, work and family and increase their ability to study. Measures such as guides that support students through a module are therefore required as a service. Such a guide, hereinafter referred to as a "self-study roadmap", serves to support students in their time management and helps lecturers to reflect on the relevant module and adapt it to the needs of the target group. Such reflection on the part of lecturers is necessary in order to take better account of the needs of participants and to better understand the role of the student. In the "Open IT" research project at the University of Applied Sciences Weserbergland, the "self-study roadmap" presented here serves as an instrument to guarantee the quality of teaching and ensure it takes into account the needs of students. This roadmap has been developed in the "Open IT" research project against the background of the following research questions that consider the perspective of students, lecturers and the university:

- How can the University of Applied Sciences Weserbergland offer a method that helps students to balance study and work?

- How can the university offer a method to internal and external lecturers that supports the incorporation and development of new course content for study programmes for working professionals?

- How can lecturers use such a method for self-study to identify temporal barriers and educational gaps when reflecting on a module?

The research questions are related to the requirements placed on the "Open IT" research project by the funding. The project is funded by the Federal Republic of Germany's Federal 
Ministry of Education and Research as part of the "Offene Hochschule" initiative and serves to remove the barriers to educational programmes in Germany and participation in education measures.

\section{Theoretical foundations}

\subsection{Role of the university}

The transfer of knowledge is an intangible service that is directly consumed and used by consumers, in this case students. A special feature here is the service recipient, who must take an active role in the service provision process (Meffert, Bruhn \& Hadwich, 2018, p. 14). In a university context, the student is thus the recipient of the "transfer of knowledge" service. The result of the service process is a university degree. As a service provider, the university is responsible for ensuring the factors relevant for service provision. For example, it must provide the corresponding infrastructure, programme administration and lecturers as mediators of knowledge. A critical success factor for completing a study programme is the active participation of students in the form of self-study, among other things (Winteler \& Forter, 2008, p. 162). Only active students can complete a study programme successfully. With the "self-study roadmap" tool, the university as a service provider offers service recipients, i.e. students, a means of support to aid them in the successful completion of their studies.

In the Bologna reform, all study programmes in Europe were revised to ensure the comparability of degrees and in particular of quality (Biggs \& Tang, 2011, p. 3). One result of the Bologna reform is that the workload per module is now expressed in ECTS points (European Credit Transfer System), where the attendance time at university lectures and the time spent on self-study are added together (Metzger, 2011, p. 238). The workload for each ECTS point is, according to the general framework, between 25 and 30 hours (Publications Office of the European Union 2015: 10). Here the university is also responsible for ensuring modules are designed appropriately in the course of study programme development. To ensure a study programme can be completed successfully, the workload must be distributed in such a way that the course can be studied.

Schmidt (2009) describes the multi-dimensional nature of quality in a university context and refers to the problem that the quality of knowledge institutions can be viewed from different perspectives, for example that of the students, the labour market or society. The interrelationship between the participation of students, the institution and lecturers is also emphasised. The particularities of the form of the programme should also be taken into consideration depending on whether the programme is a regular programme for working professionals or a credit transfer-based programme for working professionals. In the latter case in particular, the participants' differing levels of knowledge must be overcome in self-study phases and the different participants must be taken into account in alignment phases (von Zobeltitz \& Linke, 2018, p. 65). With regard to quality assurance, the university, which as an overarching institution brings together the aforementioned stakeholders, therefore has a special position. The "self-study roadmap" is a supportive tool from the perspective of quality assurance and the integration of participants. 
The use of blending learning (Graham, 2004) has been established at HSW and other educational establishments for study programmes for working professionals. This approach facilitates the effective use of self-study phases that can be enhanced by integrating e-learning content into teaching via blended learning (Garrison \& Kanuka, 2004). Virtual classrooms (Bower, 2006) can be set up for study programmes for working professionals in order to directly support students, for example in the case of queries or to discuss course content. Programmes designed in such a way can be used as an individual learning environment and supplement traditional forms of study (Kerres, 2006, p. 7). Study videos (Loviscach, 2012) and their integration in the study process are useful means (Huck \& Linke, 2016) to prepare for this exchange and to provide additional support in the self-study phase. The courses themselves, especially in the case of study programmes for working professionals, must be timed in such a way that they extend over the entire study module and offer sufficient opportunities for repetition and use of online content. This is especially important for self-study phases (Huck, Linke, \& von Zobeltitz, 2016). In this context, the lecturers engaged by the educational establishment must choose methods that best suit the relevant course content (E-Teaching.org, 2016). Approaches such as the flipped classroom are integrated into everyday study if students are to be heavily involved in the learning process (Langer, Linke \& Schimanke, 2014). The flipped classroom is a method where knowledge is acquired in self-study and applied in the classroom and can be categorised as blended learning and e-learning. However, this requires a high level of participation from students and the targeted preparation of course content. It is therefore almost mandatory for a university to time and teach course content in such a way that students can study and grasp it in a targeted manner.

\subsection{Role of lecturers}

The modern understanding of studying in a university context focuses on students and their learning processes. Barr and Tagg spoke of a paradigm shift in university teaching as early as 1995 (Barr \& Tagg, 1995, p. 13). The paradigm has moved away from the previously desired lecturer-focused transfer of knowledge and shifted towards studying. This is necessary to take account of the requirements and general conditions of life-long learning (Mocker \& Spear, 1982). Winteler and Forster (2008, p. 163) define the changing activity of lecturers as follows: "Teaching is therefore understood as a way to facilitate learning." Lecturers are required to assist students in the learning process and support self-study. Relevant modules were revised and restructured following the "ZEITLast" study in the field of "media education" at Johannes Gutenberg University in Mainz (Groß, 2011, p. 227). This study was used as a basis, among other things. The results showed that students do not invest the time required in accordance with the Bologna Process (Metzger, 2010). The module was then revised and an e-portfolio was introduced, a kind of digital folder that should support students' self-study (Groß, 2011, p. 231). E-portfolios can also guide and document learning activities for purposes of presenting observable learning activities (Kerres, 2006, p. 5). An e-portfolio can therefore serve as proof of studying and work carried out and can thus be used, for example, in addition to learning support, for transparent monitoring beyond obligatory exam performance (Kerres, 2006, p. 6). Miller and Volk provide a comprehensive overview of the use of e-portfolios in study and work and investigate the central questions as to how 
information on competences can be communicated to third parties and how an overview can be provided of the professional skills to be learnt (Miller \& Talk, 2013).

The e-portfolio is one of many ways to support students' learning processes when it comes to self-study. Lecturers are tasked with finding a suitable concept, in cooperation with the university, for designing their teaching activities as a way to facilitate learning. Lecturers are therefore responsible for filling the predefined framework with content so that a learning plan of sorts is created. This learning plan should offer an overview of the corresponding course content and put this in a temporal context so that learning progress can be monitored and corrected at an early stage, where required (Reinhaus, 2011, p. 44).

\subsection{Role of students}

As described in section 2.1, students' participation in the transfer of knowledge service process is crucial for successful study. Axelson and Flick understand student engagement to refer to the extent to which students are interested and involved in their learning activities. The level of attachment to the university institution, their course or their class also plays a significant role (Axelson \& Flick, 2011, p. 38). The study by Carini, Kuh and Klein (2006) shows a positive correlation between student engagement and learning results such as grades and critical thinking. 1,058 students at colleges and universities were surveyed for the study and their learning results investigated.

There is a special emphasis on students holding a full-time job owing to the additional burden placed on them by work. Tegtmeier and Hellert (2015) investigate by way of a study the extent to which students holding a full-time job recover from studying and working. In connection with potential problem areas in study programmes for working professionals, Koeder mentions in particular educational and social psychological reservations on the part of students. Therefore, they often do not have a personal connection with the university. Moreover, a sense of community, which would have a boosting effect on academic success, is rarely fostered among the students. Koeder emphasises in this respect the potentially isolating effect of the style of study, which could carry over into practice (Koeder, 2012). To counteract this, excellent time management and support from the university in learning processes are beneficial. Students have to learn to organise their available time for work, study-related and private activities. In this concept of study, supported self-study is essential so that students can actively and successfully participate in the transfer of knowledge service process. Support measures such as study plans, e-portfolios and the "self-study roadmap" presented here serve to facilitate and support the efficient discussion of the topic.

\subsection{Influencing factors of the "self-study roadmap" on the target groups involved}

Having considered the roles and responsibilities of the university, lecturers and students, this section summarises the three target groups involved and their significance in the creation of a "self-study roadmap". Various influencing factors can be defined from theory that have to be integrated and considered in the structure of such a roadmap. 


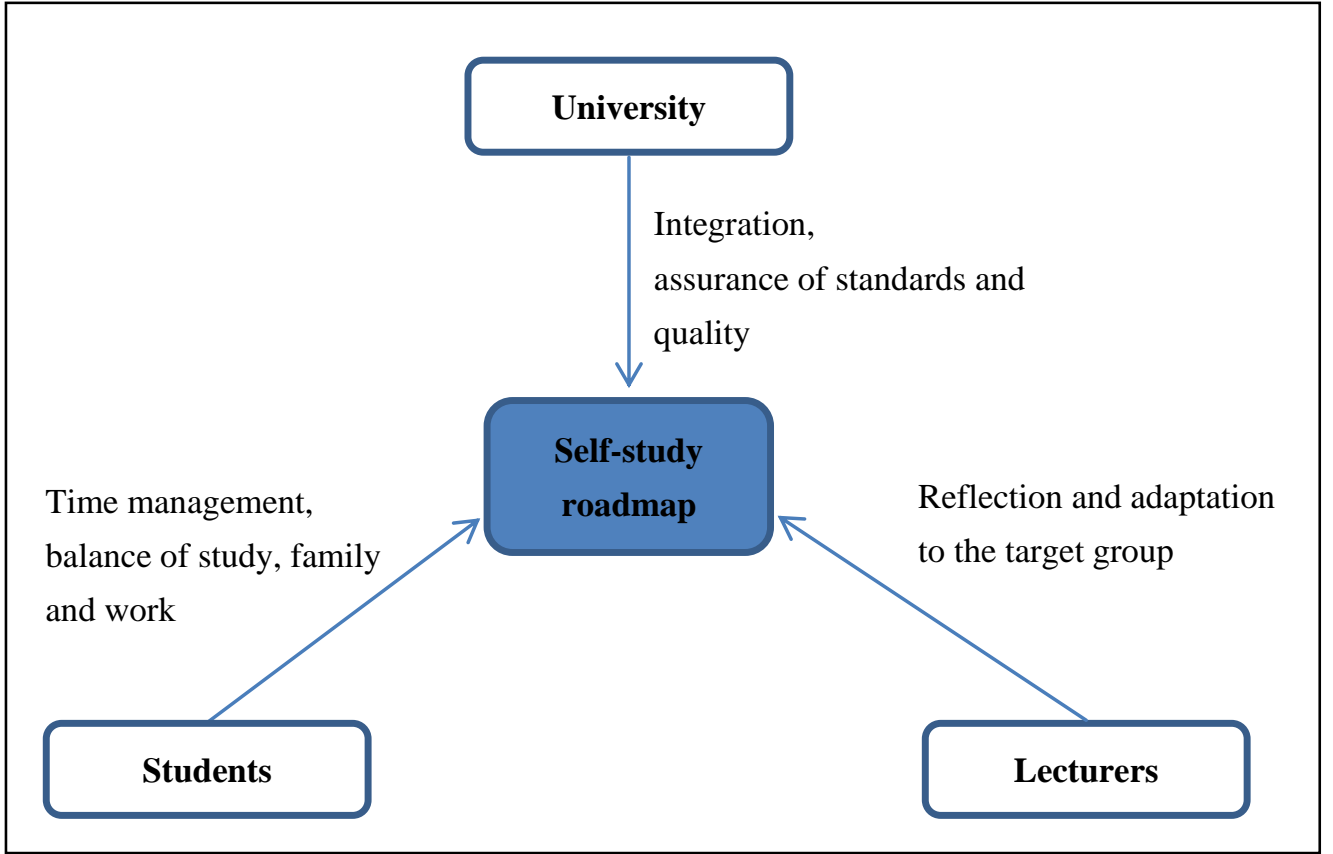

Figure 1. Influencing factors on the "self-study roadmap", own work

The "self-study roadmap" serves as a binding element between students, lecturers and the university and aims to improve teaching so that student-oriented study for working professionals can be guaranteed for purposes of quality assurance. From the university's perspective, a "self-study roadmap" can and should be used to train new lecturers. An organisational and content framework is therefore set for each module that lecturers can use as a basis in preparing modules. Moreover, the "self-study roadmap" is a tool for lecturers that helps them to reflect on the structure and content of the module. The content is thus adapted to the target group of students. A "self-study roadmap" also supports students in relation to their time management and self-control with regard to the course content to be studied. They can therefore better plan and distribute the time required for study. This should enable students to better balance study, family and work and increase their ability to study in the long term.

\section{Development of a "self-study roadmap"}

\subsection{Motivation and initial basis for the development of the "self-study roadmap"}

Three study programmes have been designed in the government-funded research project "Open IT Bachelor und Open IT Master - vom IT-Praktiker zum Bachelor Wirtschaftsinformatik und zum Master IT Business Management" (Open IT bachelor and open IT master - from IT practitioner to bachelor of business informatics and master of IT business management). Two bachelor's programmes have been developed which both have 180 ECTS points as well as a master's programme with 120 ECTS points. A special feature here is the credit transfer opportunities as those with professional experience and training can have their achievements and professional experience credited and therefore gain a degree more quickly. The first bachelor's programme is aimed at experienced IT specialists with initial IT training (Städler, von Zobeltitz, \& Linke, 2018) who can use their professional experience and initial training to reduce their study period from four to three years. This 
bachelor's programme focuses on specialisation in business informatics. The second bachelor's programme is aimed at experienced IT specialists who, in addition to initial IT training, have completed advanced further IT training at a Chamber of Industry and Commerce to become operative professionals. For this target group, the regular study period could be reduced from four to two years based on the increased potential for credit transfer. This programme specialises in IT business management. This target group can also continue on to a master's programme. Both target groups start their study in a later semester based on the credit transfer. This eliminates the normal start of the study programme, as a result of which the target group needs the kind of support in subsequent semesters that is required at an earlier stage for new students. The design of the programme orientation period must take account of this fact (Bönick, Huck, \& von Zobeltitz, 2018).

The number of ECTS points within the study programmes is divided over 17 modules plus the dissertation for the bachelor of business informatics and over eleven modules plus the dissertation for the bachelor of IT business management. Each module lasts roughly eight to nine weeks. This period includes attendance time at the university in Hamelin (usually Fridays 14:00-20:00 and Saturdays 09:00-16:30), virtual classrooms which are implemented using Adobe Connect and the relevant examinations. It also includes self-study.

The approach to and development of the "self-study roadmap" resulted from experience gained in the Open IT project in the integration and training of new lecturers and from experience gained with students. Students consistently reported how important proper time management is for self-study. This observation could be confirmed for mathematics modules in particular, for which special preparatory courses were developed for new students that required specific timing (Huck \& Linke, 2016). These and other observations gave rise to a motivation to offer students a support programme. The structure of these study programmes for working professionals means in particular that they have a high, concentrated workload. The "self-study roadmap" serves to ensure this is better managed and spread out. The development of a "self-study roadmap" was also motivated by the special timing of the modules. As explained in the previous paragraph, one module usually involves two classroom lectures and two to four Adobe Connect events over eight to nine weeks. The study workload is often concentrated at the end of this period on a test or other exam such as an assignment. To avoid this, the "self-study roadmap" should motivate students to distribute the study workload in accordance with the specifications. Consequently, they recognise when certain work has to be completed and available.

Not only does students' experience play a role in the development of the "self-study roadmap", but lecturers' experience is of particular relevance too. In the past, lecturers underwent spontaneous, non-standardised training. Objectives and the intended structure of modules were discussed in preparatory meetings between lecturers and those responsible for modules. The redesign of modules has resulted in greater freedom. The "self-study roadmap" should standardise the integration and development of modules. Best practices should therefore in particular be retained and continued for purposes of quality assurance. The "self-study roadmap" provides lecturers with an orientation framework of kinds that allows them to plan seminar-like lectures meaningfully. 


\subsection{Iterations of the "self-study roadmap" and the modules}

The creation of the "self-study roadmap" went through various stages within the research project. The basic idea was introduced at the start of the academic year in September 2016 with the integration of new lecturers. After learning about students' experiences in pre-courses, the university sought an instrument to support students. To this end, the project management created the "self-study roadmap", which was trialled in various modules. In this process, preparatory meetings were held with lecturers to reflect on the "self-study roadmap" and adapt it to the relevant course content. A sample self-study roadmap can be found below.

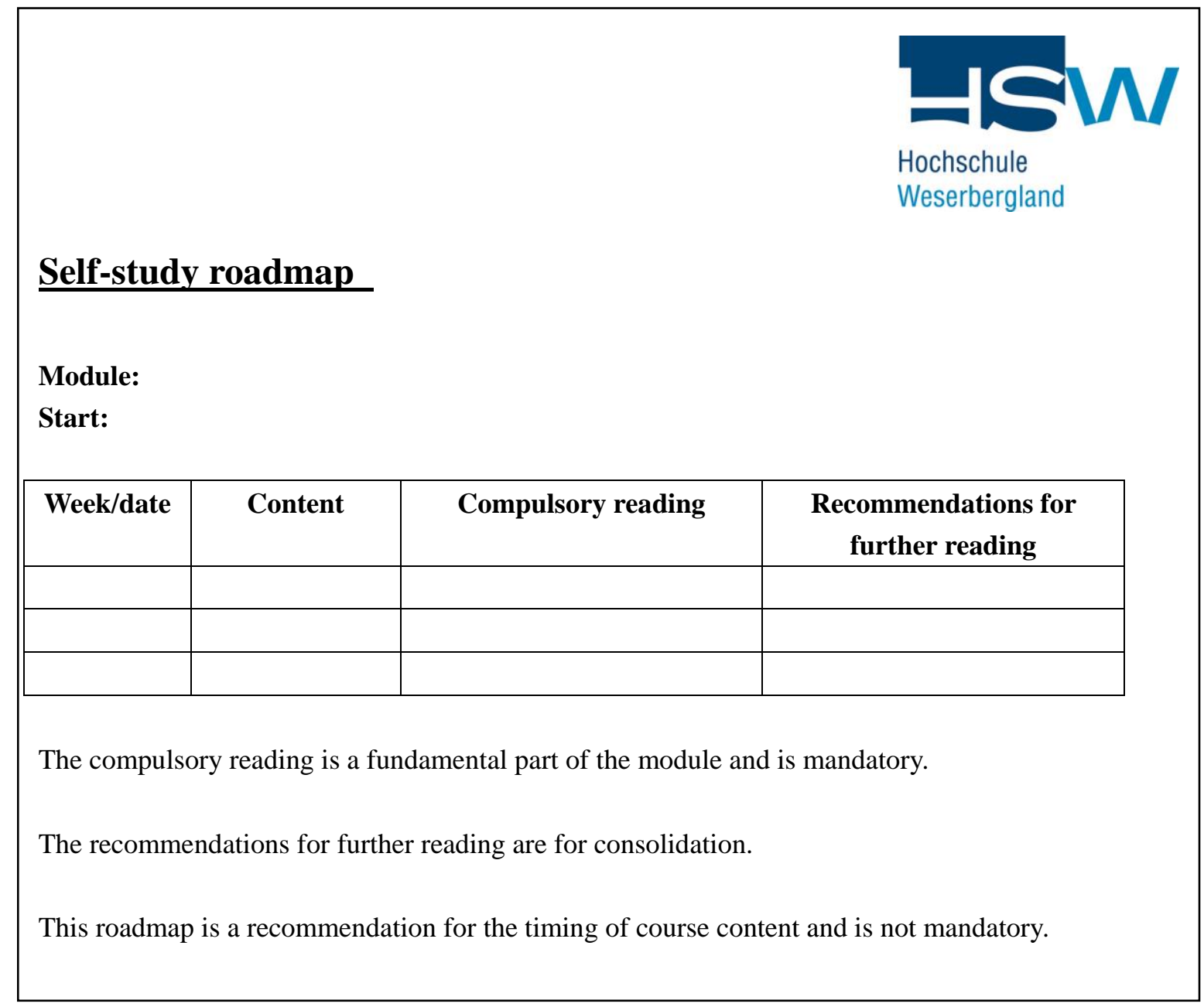

Figure 2: "Self-study roadmap" template, own work.

The "self-study roadmap" is structured in the form of a table that is filled out by the lecturers. The first column Week/date indicates when specific content is to be worked on. This could be several weeks or a specific date.

The Content column specifies the areas to be worked on on a given date or in the period. The content is supported by references to the relevant study materials. The division into compulsory reading and recommendations for further reading should help students to prioritise their work. Compulsory reading is a relevant part of the module. This significance 


\section{Macrothink}

is designated by a corresponding note. The recommendations for further reading are for consolidation. Here, lecturers are required to only recommend literature that is genuinely not mandatory for the course. This recommendation should give interested students who would like to delve more deeply into the topic the opportunity to discover content independently.

Once the "self-study roadmap" was developed, it was put into practice in modules with the result that students have worked with it. An extract from the "self-study roadmap" for the "Information Security" module is shown in the following.

\begin{tabular}{|c|c|c|c|}
\hline \\
\hline \multicolumn{4}{|c|}{ Self-study roadmap } \\
\hline \multicolumn{4}{|c|}{$\begin{array}{l}\text { Module: } 8377 \text { Information Security } \\
\text { Start: 16/10/2017 }\end{array}$} \\
\hline Week/date & Content & Compulsory reading & $\begin{array}{l}\text { Recommendations } \\
\text { for further reading }\end{array}$ \\
\hline $\begin{array}{l}\text { 18/10/2017 } \\
18: 30-19: 30\end{array}$ & $\begin{array}{l}\text { 1. Online session: } \\
\text { Questions on the process, } \\
\text { examination and content } \\
\text { orientation, self-study and } \\
\text { content, introduction to } \\
\text { working with sources }\end{array}$ & & \\
\hline $\begin{array}{l}16 / 10 / 2017- \\
09 / 11 / 2017\end{array}$ & $\begin{array}{l}\text { I. Information security } \\
\text { II. Focus on data } \\
\text { protection }\end{array}$ & $\begin{array}{l}\text { Slides 1-95, } \\
\text { - German Basic Law Articles 1-2 } \\
\text { - Federal Data Protection Act } \\
\text { - German Penal Code (StGB) Sections } \\
\text { 201, 201a, 202, 202a, 202b, 202c, } \\
\text { 202d, 203, 204, } 206 \\
\text { - German Unfair Competition Act } \\
\text { (UWG) Section } 17 \\
\text { - German Art Copyright Act } \\
\text { (KunstUrhG) Sections 22-23 }\end{array}$ & $\begin{array}{l}\text { "The company data } \\
\text { protection officer" } \\
\text { Purpose of the } \\
\text { institution, forms of } \\
\text { institutionalisation, } \\
\text { tasks and areas of } \\
\text { conflict Björn Busch } \\
\text { / Sina Leyendecker }\end{array}$ \\
\hline
\end{tabular}

Figure 3: Extract from the "self-study roadmap" for the "Information Security" module, own work

The diagram shows that the dates are listed in chronological order. It can also be seen whether course content is delivered in lectures or online sessions on Adobe Connect. Students quickly gain an overview of which topics are discussed at which times. Compulsory reading 
and additional literature are also indicated, allowing students to carry out targeted preparation.

\subsection{Collaboration process between the university, lecturers and students}

As presented in figure 1, the "self-study roadmap" is an instrument created in collaboration between the university and lecturers that is used for the successful cooperation of lecturers and students. The following figure visualises the self-study roadmap process.

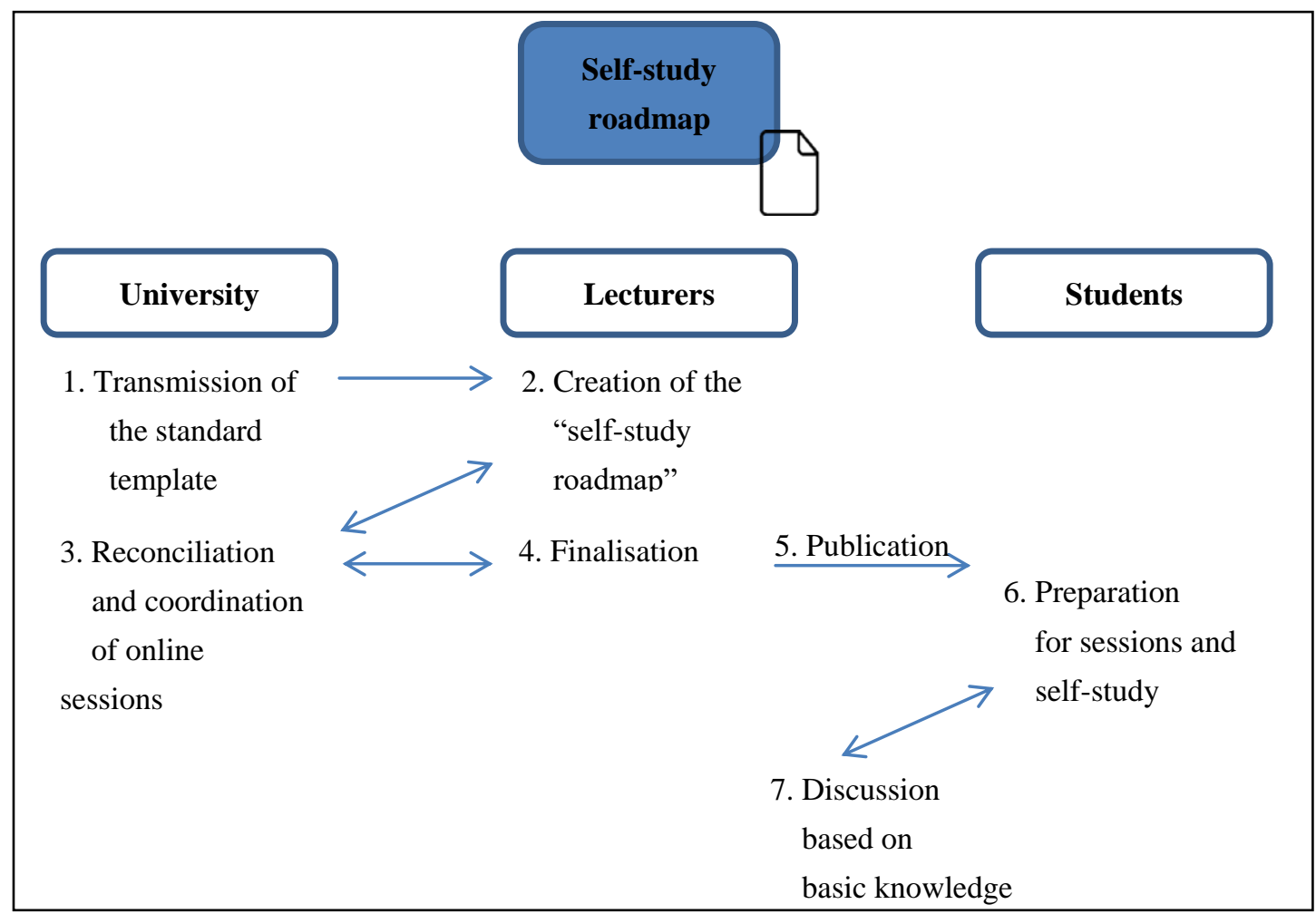

Figure 4: "Self-study roadmap" process, own work.

The first process step, transmission of the standard template, takes place between the university and the lecturers. Corresponding communication and clarification is required for this. When new lecturers are recruited, the standard template of the "self-study roadmap" must be sent at an early stage.

As a result, the lecturer can participate in the second step, creation of the "self-study roadmap", and module planning. As all modules in the Open IT study programme have or had to be redesigned, standardisation by means of the "self-study roadmap" is expedient. The redesign was necessary as the course content had not previously been taught at all, or at least not to working professionals. The lecturer divides the course content into topics and also sets out the relevant literature for preparation and/or consolidation. The dates for the online sessions on Adobe Connect are also entered.

In the third step reconciliation and coordination of online sessions, the lecturer and the person responsible for the module coordinate the "self-study roadmap" in a personal meeting. 
The two-man rule allows any inconsistencies to be discovered here. The dates for the online sessions on Adobe Connect are also definitively coordinated. This takes place in consultation with the study organisation and the e-learning trainer. This process step also serves as a means of reflection. Various aspects can be critically scrutinised here, including the logical order. Lecturers and those responsible for modules can also reflect on whether the content is arranged meaningfully. Temporal aspects should also be reviewed in terms of whether, for example, there is sufficient time for consolidation literature and whether the time required for preparation and follow-up is justified. It is also considered whether the online sessions are planned in a manner that complements the lectures and the submission and processing deadlines for the module's assessments. Further issues relating to the order of events can also be discussed. These may relate to the number of hours, the scope of the self-study phase and the distribution of hours over the length of the module, for example.

The lecturer works on the last details in the fourth step of finalisation. The final version may still be discussed with one of the previous contact persons and is definitively approved by the person responsible for the study programme insofar as extensive reworking was required.

Before the module begins, the "self-study roadmap" is published in Ilias, HSW's study management system, making it available to students. Students thus have the opportunity to look at the module roadmap and ask questions, where applicable, at an early stage before the module begins. This also creates sufficient buffer space for the procurement of suitable literature and students do not have to deal with extensive descriptions of courses. Early publication is also required and useful so that students can plan for upcoming study phases in their work and private lives.

Students must complete the sixth step in the "self-study roadmap" process, preparation for sessions and self-study. The roadmap ensures that students' self-study is unplanned no longer. They have an overview of what they are working on, preparing for or following up on and at what time. This makes the content of classroom-based events more relevant, allowing for specific knowledge gaps or outstanding issues to be identified more quickly.

The aforementioned gaps and issues can then be clarified with the lecturer in the next classroom-based or online event in the seventh step, discussion based on basic knowledge. The "self-study roadmap" thus supports discussions between lecturers and students.

\section{Development into the portfolio roadmap}

The e-portfolio was discussed in section 2.2 as a potential form of studying that supports and guides students in the learning process. With respect thereto, the development of the "self-study roadmap" into a portfolio roadmap is to be discussed in this section. Lecturers created a corresponding portfolio roadmap for the module "Digitisation II: - Working and studying in a changing world". In this context, we can speak of a portfolio if the "self-study roadmap" is extended to include self-study tasks and questions. The specific tasks should serve to verify learning results and ensure direct preparation for classroom-based events. The portfolio roadmap makes extensive reference to additional information. Unlike the "self-study roadmap" presented in the foregoing, specific references are made here to 
passages or articles that should specifically be worked on. The students are also given specific instructions. Moreover, the materials are contextualised in connection with the current module. The materials to be worked on and read are made available to students. The following figure shows a sample task from a portfolio roadmap.

\section{Calendar week 22}

Please read the text appendix3_New requirements and burdens carefully. Make notes on the author's key statements and argument structure (roughly one side of A4).

Which conclusions do you draw from this text as the managing director of a medium-sized company (predominantly knowledge work) and why? And as the employee representative of the same company? And as the personnel developer? And as an employee?

Please make written notes (roughly one side of A4 for each perspective).

Figure 4: Extract from the portfolio roadmap for the "Digitisation II" module, own work.

Unlike the "self-study roadmap" for the "Information Security" module in section 3.2, a temporal reference can be seen here. The task in figure 4 refers to calendar week 22 . In addition to the literature provided, appendix3_New requirements and burdens, there are specific tasks. The findings are to be written on an A4 page for each task.

The approach of the portfolio roadmap described has advantages and disadvantages for the roadmap's different stakeholders, students and lecturers. On the positive side, self-study has been designed efficiently. The requirements and tasks relating to specific texts allow students to work on the course content in a more controlled, and therefore focused, manner. Students know what they should and need to focus on and exactly what is expected from them. Writing this down ensures that knowledge is further processed and secured. Consequently, learning results can be controlled in a more targeted manner and discussed in attendance phases. On the whole, it should be noted from a student perspective that they know from the outset what is to be studied and worked on, guaranteeing a high level of transparency in the study module. This detailed breakdown of the workload also allows the subject matter to be divided in such a way that facilitates better time management. All in all, this gives students a high service level and intense support from lecturers. There are still some critical points to be noted, however: A detailed portfolio can seem very regimented to students and lecturers. The compartmentalisation of tasks and the specific timescale may reinforce this impression. This reduces the requirements placed on students and their skills in the area of personal responsibility. Academic study should motivate students to study and work independently. A detailed and specific portfolio makes it difficult to focus on individual interests. Students may feel like too much is expected of them at the start of the module because of the total volume and scope. They will see all requirements at once, which may seem daunting. In comparison, 
the study workload in traditional modules is concentrated at the end with a test or assignment. This study workload can often not be assessed at the outset. The increased burden on lecturers to create such a detailed portfolio roadmap should also not be forgotten.

\section{Conclusion}

Studying, as a service for the transfer of knowledge, requires the collaboration of the university, lecturers and students. Students are in particular heavily involved in the service process as service recipients. They must actively accept the course content delivered by lecturers to complete their degrees successfully. Students holding a full-time job are under high pressure in particular, caused by the triple burden of study, work and family. Targeted support of self-study is required and essential to help students to balance the three.

HSW's Open IT project, which has overseen the development and implementation of two bachelor's programmes in the field of business informatics, relies on a "self-study roadmap" to assure quality and support students holding a full-time job. In this process, a module is broken down temporally and the literature and additional tasks to be worked on are provided to allow for an efficient and controlled self-study process.

The positive feedback from students and lecturers can be emphasised on the whole. For lecturers, the self-study roadmap serves as a means to reflect on their generally newly developed modules. Students benefit from support in their learning processes and time management. The portfolio contains specific and comprehensive tasks. Students perceive this to be a greater burden, which must be taken into account in the analysis of the "self-study roadmap" or portfolio. A potential reason for this is that the entire study workload in the relevant module is visible straightaway. Simplified training remains to be mentioned for the university. The "self-study roadmap" provides new lecturers with a practical framework to develop and prepare a module.

Based on the positive experience gained in the Open IT business informatics programmes, a transfer of the "self-study roadmap" to the business administration programme for working professionals is being considered. All lecturers in all study programmes for working professionals should therefore be provided with a uniform template to guarantee the uniform design of roadmaps. University employees are also being put in a position to support all lecturers in the creation and provision of the self-study roadmaps in order to create acceptance for the establishment thereof. In this way, the "self-study roadmap" should be firmly integrated in the onboarding process for new lecturers so that their training at HSW can be standardised and simplified. HSW is planning a workshop for reflecting on previous use of the "self-study roadmap" in order to constantly improve and develop the same. The roadmap should likewise be adapted both in terms of form and the required content to the needs of students, lecturers and the university in an iterative process.

\section{Acknowledgement}

The project underlying this document was funded by the Federal Ministry of Education and Research Germany under funding code $16 \mathrm{OH} 21005$. The author is responsible for the content of this publication. 


\section{References}

Axelson, R. D., \& Flick, S. (2011). Defining Student Engagement. Change: The Magazine of Higher Learning, 43, 38-43. https://doi.org/10.1080/00091383.2011.533096

Barr, R. B., \& Tang, C. (1995). From teaching to learning: A new paradigm for undergraduate education. Change: The Magazine of Higher Learning, 27, 12-25

Biggs, J., \& Tang, C. (2001). Teaching for Quality Learning at University (4 ${ }^{\text {th }}$ ed.). New York: Open University Press

Bönick, L., Huck, S., \& von Zobeltitz, A. (2018). Die zeitliche Abfolge und Ausrichtung der ersten Semester für berufsbegleitende Anrechnungsstudiengänge, in: Städler, M., von Zobeltitz, A. (Eds.). Akademische Weiterbildung für IT-Fachkräfte. Norderstedt: Books on Demand, 81-92.

Bower, M. (2006). Virtual Classroom Pedagogy, ACM SIGCSE Bulletin, 38(1), 148-152. https://doi.org/10.1145/1124706.1121390

Carini, R.M., Kuh, G.D., \& Klein, S.P. (2006). Student Engagement and Student Learning: Testing the Linkages. Research in Higher Education, 47, 1-32. https://doi.org/10.1007/s11162-005-8150-9

E-Teching.org (2016): Wie verändert Videoeinsatz die Lehre? [Online] Available: https://www.e-teaching.org/community/communityevents/onlinepodium/fuer-immer-onli ne-wie-veraendert-der-videoeinsatz-die-lehre (June 25, 2018)

Garrison, D. R., \& Kanuka, H. (2004). Blended Learning: Uncovering is transformative potential, in: higher education, Internet and Higher Education, 7, 95-105. https://doi.org/10.1016/j.iheduc.2004.02.001

Graham, C. R. (2004). Blended Learning Systems: Definition, Current Trends, and future directions, in: Bonk, C. J., Graham, C. R. (Eds.). Handbook of blended learning: Global perspectives, local design. San Francisco: Pfeiffer

Groß, L. (2011). Hochschuldidaktische Interventionen im Studienschwerpunkt Medienpädagogik, in: Schulmeister, R., Metzger, C. (Eds.). Die Workload im Bachelor. Zeitbudget und Studierverhalten, Eine empirische Studie. Münster: Waxmann

Huck, S., \& Linke, K. (2016). Integration of Best Practices and Requirements for Preliminary E-Learning Courses. International Journal of Educational and Pedagogical Sciences, 10(3), 966-973

Huck, S., Linke, K., \& von Zobeltitz, A. (2016). Das Inverted-Classroom-Model in virtuellen Klassenräumen. [Online] Available: https://www.e-teaching.org/etresources/pdf/ erfahrungsbericht_2016_huck_linke_von_zobeltitz_inverted_classroom.pdf (June 25, 2018)

Kerres, M. (2006): Potenziale von Web 2.0 nutzen, in: Hohenstein, A./ Wilbers, K. (Eds.). Handbuch E-Learning, Munich: DWD 
Koeder, K. W. (2012). Studienmethodik, (5. ed.). Munich: Franz Vahlen

Langer, V., Linke, K., \& Schimanke, F. (2014). Improvement of Self-directed Learning by Using the Inverted Classroom Model for a basic Module in Business Computer Science, in: The Inverted Classroom Model - the 3rd German ICM-Conference-Proceedings, 73-82. Munich: Oldenbourg.

Loviscach, J. (2012). Videoerstellung für und Erfahrungen mit dem ICM, in: Das Inverted Classroom Model, 25-38. Munich: Oldenbourg.

Miller, D., \& Volk, B. (2013). E-Portfolio an der Schnittstelle von Studium und Beruf. Münster: Waxmann

Meffert, H., Bruhn, M., \& Hadwich, K. (2018). Dienstleistungsmarketing, GrundlagenKonzepte - Methoden (9. ed.). Wiesbaden: Springer Gabler

Metzger, C. (2010). ZEITLast: Lehrzeit und Lernzeit. Studierbarkeit von BA-/BSc-Studiengängen als Adaption von Lehrorganisation und Zeitmanagement unter Berücksichtigung von Fächerkultur und neuen Technologien, in: Seiler Schiedt, E., Mandel, S., Rutishauser, M. (Eds.). Digitale Medien für Lehre und Forschung. Münster: Waxmann, 287-302

Metzger, C. (2011). Studentisches Selbststudium, in: Schulmeister, R., Metzger, C. (Ed.). Die Workload im Bachelor. Zeitbudget und Studierverhalten, Eine empirische Studie. Münster: Waxmann, 237-278

Mocker, D. W., Spear, G. E. (1982). Lifelong Learning: Formal, Nonformal, Informal, And Self-Directed. Information Series No. 241, Columbus: ERIC Clearinghouse on Adult, Career, and Vocational Education

Publication Office of European Union (2015). ECTS Leitfaden. [Online] Available: https://ec.europa.eu/education/ects/users-guide/docs/ects-users-guide_de.pdf

Reinhaus, D. (2011). Lerntechniken. Freiburg: Haufe

Schmidt, B. (2008). Qualität der Lehre an Hochschulen. Zeitschrift für Pädagogik, 53, $156-170$

von Zobeltitz, A., \& Linke, K. (2018). Anrechnungsstudiengänge - eine Herausforderung für berufsausgebildete PraktikerInnen und Hochschulen? in: Städler, M., von Zobeltitz, A. (Eds.). Akademische Weiterbildung für IT-Fachkräfte. Norderstedt: BoD, 57-66.

Winteler, A., \& Forster, P. (2008). Lern-Engagement der Studierenden: Indikator für die Qualität und Effektivität von Lehre und Studium. Das Hochschulwesen, 56(6), 162-170

\section{Copyright Disclaimer}

Copyright reserved by the author(s).

This article is an open-access article distributed under the terms and conditions of the Creative Commons Attribution license (http://creativecommons.org/licenses/by/3.0/). 